\title{
Workhsop Peningkatan Profesionalisme Guru SD Melalui Kompetensi Membuat Media Pembelajaran IPS
}

\author{
Jumardi $^{1}$, Andi ${ }^{2}$, Rizki Dwi Siswanto ${ }^{3}$ \\ ${ }^{1,2}$ Pendidikan Sejarah, FKIP Universitas Muhammadiyah Prof. DR. HAMKA \\ ${ }^{3}$ Pendidikan Matematika, FKIP Universitas Muhammadiyah Prof. DR. HAMKA \\ jumardi@uhamka.ac.id
}

\begin{abstract}
ABSTRAK
Pembelajaran akan lebih bermakna jika materi yang disampaikan oleh guru mampu membawa kesenangan tersendiri bagi peserta didik. Kendala yang dihadapi guru dalam pembelajaran adalah kemampuan guru dalam menggunakan media invoatif. Media inovatif sangat dibutuhkan bagi siswa dalam pembelajaran supaya lebih menarik. Pengabdian dilakukan dengan memberikan pelatihan bagi guru dengan menggunakan permainan monopoli yang dapat dibuat secara sederhana dengan program power point. Pelatihan pembuatan media pembelajaran monopoli ini akan membantu guru dalam membuat siswa tertarik akan materi pembelajaran yang diberikan. Metode pengabdian adalah dengan metode pelatihan. Guru-guru dibimbing untuk membuat media pembelajaran monopoli. Pelaksanaan pelatihan di fokuskan pada guru SD Negeri Pasar Baru 5 Pagi. Hasil yang dicapai, guru-guru mampu menghadirkan media pembelajaran menarik dengan menggunakan media pembelajaran monopoli dan media pembelajaran dapat disesuaikan dengan mata pelajaran yang ada dilingkungan sekolah.
\end{abstract}

Kata kunci: profesionalisme guru, media pembelajaran IPS, sekolah dasar

\section{ABSTRACT}

Learning will be more meaningful if the material delivered by the teacher is able to bring its own fun for students. The obstacle faced by teachers in learning is the ability of teachers to use invoative media. Innovative media is really needed for students in learning to be more interesting. Dedication is done by providing training for teachers using monopoly games that can be made simply with a power point program. This monopoly learning media creation training will help teachers in making students interested in the learning material provided. The service method is the training method. Teachers are guided to create monopolistic learning media. The training is focused on teachers at Pasar Baru 5 Elementary School. The results achieved, teachers are able to present interesting learning media by using monopolistic learning media and learning media can be adapted to existing subjects in the school environment.

Keywords: teacher professionalism, social media learning media, elementary schools

\section{PENDAHULUAN}

Upaya mencerdaskan kehidupan bangsa dan meningkatkan kualitas manusia Indonesia merupakan tugas guru dan dosen seperti tertuang dalam UU RI No.14 Tahun 2005 tentang Guru dan Dosen, Guru mempunyai fungsi, peran, dan kedudukan yang sangat strategis dalam pembangunan nasional di bidang Pendidikan. Sementara PP 18 Tahun 2007 tentang guru dinyatakan bahwasannya kompetensi yang harus dimiliki oleh guru meliputi kompetensi pedagogik, kompetensi kepribadian, kompetensi sosial dan kompetensi profesional yang diperoleh melalui pendidikan profesi (Karmizan, 2018). Istilah guru profesioanl menjadi bagian penting dalam kesuksesan pembelajaran dikelas. Mulyasa (Harjum, 2018) menjelaskan bahwa guru profesional adalah guru yang mampu membentuk peserta didik sesuai dengan karakteristik masing-masing siswa. Hal ini didukung dengan diberlakukannya kurikulum 2013 oleh pemerintah.

Kurikulum 2013 telah mengubah sistem pendidikan Indonesia yang mengandalkan pembelajaran berpusat pada guru (Teacher Centered Learning) menjadi pembelajaran berpusat pada peserta didik (Learner Centered Learning), dan menuntut kreativitas guru dalam pengelolaan kelas. Guru dituntut untuk menggunakan berbagai macam metode, media pembelajaran, dan sumber belajar yang akan 
mengarahkan pada pembelajaran yang berpusat pada peserta didik. Pembelajaran sudah tidak lagi menjadikan guru sebagai satu-satunya sumber belajar, tetapi sebagai fasilitator dalam mengembangkan potensi dan bakat siswa.

Hasil observasi Handayani terhadap peserta PLPG rayon 16, bahwa sebagian besar kurang memahami dan menerapkan keterampilan harus dilaksanakan ketika sedang mengajar di depan kelas, maka proses pembelajaran masih didominasi (terpusat) pada guru (Handayani, 2014).

Pemilihan media dan metode, selain disesuaikan dengan tujuan pembelajaran, juga disesuaikan dengan karakteristik siswa dan menyalurkan pesan dari pembelajaran. Santyasa menjelaskan sebagaimana dikutip Anis, Media adalah segala sesuatu yang dapat digunakan untuk menyalurkan pesan sehingga dapat merangsang perhatian, minat, pikiran dan perasaan siswa sehingga dapat dicapai tujuan belajar yang diharapkan (Suprapto, 2013). Siswa yang berada di jenjang Sekolah Dasar seharusnya diberikan metode dan media yang berbeda dengan siswa di Sekolah Menengah Pertama atau Sekolah Menengan Atas. Siswa yang memiliki keterbatasan fisik akan diberikan metode dan media yang berbeda dengan siswa normal.

Dikutip Tejo, Association for Education and Communication Technology (AECT), mengartikan kata media sebagai segala bentuk dan saluran yang dipergunakan untuk proses informasi. National Education Association (NEA) mendefinisikan media sebagai segala benda yang dapat dimanipulasikan, dilihat, didengar, dibaca atau dibicarakan beserta instrumen yang dipergunakan untuk kegiatan tersebut. Sedangkan Heinich, dkk (1982) mengartikan istilah media sebagai "the term refer to anything that carries information between a source and a receiver" (Nurseto, 2011).

Penggunaan metode dan media yang tepat akan mampu membangkitkan kreativitas siswa, sehingga pembelajaran tidak hanya melakukan transfer of knowledge tetapi juga transfer of skill dan transfer of attitude. Oleh karena itu, seorang guru diharuskan memiliki kompetensi untuk merancang media yang inovatif dan kreatif, sehingga pembelajaran bisa optimal sehingga dapat dijadikan sumber informasi dan komunikasi. Media pembelajaran memiliki kontribusi dalam meningkatkan mutu dan kualitas pembelajaran (Khairunnisa, Hakam, \& Amaliyah, 2018). Sebagai ujung tombak pembelajaran, guru merupakan pihak yang terlibat langsung dalam proses pembelajaran di kelas dan memiliki peran yang sangat vital (Muhson, 2004).

Salah satu mata pelajaran yang membutuhkan inovasi media pembelajaran, adalah pembelajaran IPS. Siswono \& Djulaiqha (2017) menjelaskan bahwa permasalahan pembelajaran IPS adalah pada lulusan guru yang bukan berlatar belakang pendidikan IPS, sehingga dirasa kurang memberi makna dalam setiap materi IPS yang disampaikan. Selain itu pemanfaatan media bagi pembelajaran IPS pun dirasa kurang dipahami oleh guru IPS di satuan pendidikan dasar.

Permasalahan yang terjadi pada SD Negeri Pasar Baru 5 Pagi adalah kurangnya kemampuan guru - guru dalam memanfaatkan teknologi informasi, sementara murid murid setingkat SD dianggap mahir menggunakan teknologi. Guru - guru lebih senang menggunakan media gambar, buku guru atau sejenisnya dalam menjelaskan kepada muridmurid. Pembelajaran inovatif merupakan pembelajaran yang lebih bersifat student centered dengan memberikan peluang kepada peserta didik untuk lebih mengkonstruksi pengetahuan secara mandiri (Inggriyani, Fazriyah, Hamdani, \& Purbasari, 2020).

Materi IPS yang padat dan abstrak, disertai dengan penyajian yang berpusat pada guru, akan menjadikan siswa bosan, sehingga tujuan pembelajaran tidak tercapai. Dalam IPS ada empat kompetensi yang harus dikuasai oleh siswa, yaitu B (Behavior), A (Attitude), S (Skill), dan K (Knowledge). Sapriya (Harini \& Usman, 2019) mengemukakan pembelajaran IPS lebih dipentingkan pada dimensi pedagogik dan psikologis serta karakteristik, sehingga kemampuan berpikir peserta didik bersifat holistik. Keterampilan yang dianggap bersinergi tersebut adalah keterampilan bertanya. Selama ini, guru IPS hanya menekankan pada satu kompetensi, yaitu knowledge atau pengetahuan. Sedangkan untuk kompetensi yang lain, masih belum menjadi prioritas. Pemahaman inilah yang mendasari minimnya guru IPS yang menggunakan media inovatif dan kreatif dalam pembelajaran, karena dianggap tidak mampu mewakili materi. Problematika dalam pembelajaran di atas, mendorong perlunya diadakan pelatihan pembuatan media pembelajaran.

Kegiatan workshop dan pelatihan tentang pembuatan media pembelajaran yang disesuaikan dengan tema pembelajaran agar menarik, merupakan salah satu upaya untuk 
meningkatkan kemampuan pedagogik dan mengasah kreativitas para guru IPS di wilayah wilayah Kecamatan Sawah Besar, Jakarta Pusat. workshop ini juga dapat menjadi solusi bagi sekolah dan guru yang belum memiliki kemampuan membuat media pembelajaran yang menarik dan efisien.

\section{METODE KEGIATAN \\ Metode yang digunakan metode} pelatihan yang dilaksanakan di SD Negeri Pasar Baru 5. Pengabdian dilaksanakan 20 Pebruari sampai dengan 20 Maret 2020. Bentuk pengabdian adalah melakukan pelatihan pembuatan media pembelajaran monopoli bagi pelajaran IPS di sekolah dasar. Ruang lingkup dan objek pengabdian ini adalah seluruh guru di SD Negeri Pasar Baru 5. Pelatihan menurut Mathis dalam Elfrianto adalah "Pelatihan adalah suatu proses dimana orang-orang mencapai kemampuan tertentu untuk membantu mencapai tujuan organisasi. Oleh karena itu, proses ini terikat dengan berbagai tujuan organisasi, pelatihan dapat dipandang secara sempit ataupun luas" sementara menurut Andrew F. Sikula yang dikutip oleh (Mangkunegara, 2000) mengatakan :"Training is a short term educational process utilizing systematic and organized prodecure by wich non managerial personel learn technical knowledge and skills for a definite pyrpose". (Latihan adalah suatu proses pendidikan jangka pendek dengan menggunakan prosedur yang sistematis dan terorganisir, sehingga karyawan operasional belajar pengetahuan teknik pengerjaan dan keahlian untuk tujuan tertentu) (Elfrianto, 2016). Dengan demikian pelatihan adalah proses pembelajaran yang terrencana untuk mencapai tujuan tertentu. Tahapan kegiatan pelatihan pembuatan media pembelajaran monopoli pelajaran IPS bagi guru di SD Negeri Pasar Baru 5, perencanaan kegiatan, pelaksanaan kegiatan di sekolah, pembimbingan dan evaluasi.

\section{HASIL \& PEMBAHASAN}

Pelaksanaan Kegiatan pengabdian masyarakat yang dilakukan oleh tim (dosen dan mahasiswa) pada tanggal 5 Agustus 2019 di SDN 05 Pasar Baru Jakarta Pusat. Berlokasi di J1. Pintu Besi I No 42, Kel. Sawah Besar, Daerah Khusus Ibukota Jakarta 13730. Kegiatan pelatihan diikuti oleh 20 Guru kelas dan guru bidang studi. Dalam pelaksanaan pengabdian tersebut melibatkan 7 orang mahasiswa semester 4 yang telah dibekali matakuliah inovasi pembelajaran.

Kegiatan pengabdian Peningkatan Profesionalisme Guru SD Melalui Kompetensi Membuat Media Pembelajaran di SDN 05 Pasar Baru Jakarta Pusat dimulai Pada Pukul 13.00. Kegiatan dibuka oleh Ibu Tuti Suciati selaku Kepala Sekolah Dasar Negeri 05 Pasar Baru. Acara dilanjutkan oleh tim pengabdian dengan menjelaskan pentingnya media pembelajaran sebagai alat yang yang digunakan untuk mempermudah guru dalam menyampaikan materi pembelajaran.

Sampai saat ini media pembelajaran interaktif masih belum berkembang atau belum banyak guru yang menggunakannya. Selain masalah waktu pembuatan media, masalah teknologi yang kurang dikuasai oleh guru menyebabkan media pembelajaran interaktif jarang digunakan. Selesai menjelaskan materi terkait apa itu media pembelajaran dan pentingnya media pembelajaran, peserta pengabdian diberikan praktek penggunaan media pembelajaran yang telah tim buat.

Media pembelajaran yang dilaksanakan mengadopsi permainan monopoli yang akrab dengan dunia anak. Barkley menjelaskan penggunaan media monopoli menuntut untuk membagi peserta didik menjadi beberapa kelompok kecil dengan kemampuan yang beragam dan berbeda tingkat kemampuan (Suprapto, 2013). Permainan monopoli diubah dengan menggunakan materi sejarah. Kemudian Peserta dibagi menjadi 4 kelompok dengan jumlah pemain terdiri dari 4 orang. Setiap permainan dibekali dengan hukuman dan pertanyaan. Hukuman disesuaikan dengan tema dalam pembelajaran. Hukuman dapat berupa menyanyikan lagu wajib atau lagu daerah. Dapat juga berupa pertanyaan tentang pakaian daerah atau tentang keluarga. Apabila salah satu pemain sudah ada yang menyampai finish, permainan dianggap selesai dan selanjutnya guru dapat merefleksi hasil permainan monopoli sebagai penutup pembelajaran.

Setelah melakukan praktik menggunakan monopoli untuk media pembelajaran, kegiatan dilanjutkan dengan workshop pembuatan pembuatan media pembelajaran monopoli. Dalam kegiatan ini, peserta menggunakan laptop yang sebelumnya sudah mereka persiapkan, selama dua jam peserta dibimbing bagaimana cara pembauatn media Monopoli,

Keseriusan peserta dalam mempraktekan pembuatan media pembelajaran 
monopoli dengan tema sesuai dengan bidang studi masing-masing. Peserta terdiri dari berbagi guru kelas dan guru bidang studi, harapan peserta pada pelatihan ini adalah mereka berharap akan ada pelatihan-pelatihan lain untuk meningkatkan kompetensi mereka dalam melakukan kegiatan pembelajaran di dalam kelas.

Pada pukul 16.00 kegiatan pengabdian masyarakat selesai dilaksanakan para peserta telah mampu mempraktekan bagaimana membuat media mmonopoli sebagai pembelajaran.

\section{Langkah-Langkah Membuat} Monopoli Pembelajaran Menggunakan Microsoft Power Point 2010

1. Buka lembar kerja Microsoft Power Point, pilih Windows lalu cari Power Point:

2. Setelah terbuka kemudian kosongkan slide yang ada. Pilih slide kemudian klik kanan lalu pilih Layout, dan cari Blank lalu klik kiri.

3. Untuk selanjutnya atur ukuran slide menjadi A3 atau ukuran lainnya dengan cara pilih design lalu klik Page Setup.

4. Jika sudah maka akan muncul tampilan seperti di bawah untuk memilih kertasnya, kemudian pilih A3 lalu OK

5. Kemudian buat persegi diantara 4 sudutsudut slide menggunakan Rectangle, caranya pilih Insert, Shapes lalu Rectangle

6. Selanjutnya letakan persegi tersebut ke sudut slide sambil menekan tombol Shift di keyboard agar sudut antar perseginya sama.

7. Jika rectangle yang dibuat dirasa tidak sama setiap sisinya bisa diatur melalui format dengan cara, klik Rectangle, pilih Format lalu atur di size dengan ukuran yang sama panjang dan lebarnya.

8. Copy rectangle awal dan pindahkan ke setiap sudut yang ada, menggunakan $\mathrm{Ctrl}+\mathrm{C}$ dan $\mathrm{Ctrl}+\mathrm{V}$

9. Tahap selanjutnya pilih Insert klik Shapes lalu pilih Rounded Rectangle

10. Jika sudah lalu letakan Rounded Rectangle diantara rectangle-rectangle yang sudah dibuat tadi, namun ukuran panjang Ruonded Rectangle diusahakan lebih pendek disbandingkan dengan Rectangle.

11. Kemudian copy Rounded Rectangle dan pindahkan kesetiap bagian-bagian yang ada disekitar rectangle, seperti gambar berikut

12. Setelah itu buat Rounded Ractengle yang lebih kecil untuk bagiaan penamaan, lalu copy sampai memenuhi semua bagian.

13. Tahap selanjutnya adalah memasukan gambar sesuai dengan materi yang dipilih dengan cara, Klik Insert pilih Picture kemudian cari dimana kita menyimpan gambar yang akan kita masukan ke dalam rectangle tersebut.

14. Pilih gambar yang telah ada di slide kemudia tekan Ctrl dan X pada keyboard secara bersamaan, setelah gambarya menghilang lalu klik rectangle yang akan dimasukan gambar tersebut kemudian klik kanan pilih format shape lalu klik hingga muncul tampilan lainnya

15. Jika sudah muncul tampilan di bagian Fill cari Picture of texture fill kemudian klik lalu klik tulisan Clipboard maka gambar yang kita masukan tadi akan bepindah ke dalam rectangle

16. Kemudian penuhi rectangle dengan gambar yang sesuai dengan materi yang akan dimasukan, jika terdapat permasalahan seperti gambar yang tidak sinkron atau berputar bisa diatur melalui pilihan yang ada di bawah Clipboard

17. Jika semua gambar telah dimasukan selanjutnya memberikan keterangan pada gambar dibagian yang telah disediakan, caranya cukup mengklik rectangle yang ingin dimasukan tulisan kemudian lngsung tekan huruf yang ingin dimasukan ke keyboard, maka tulisannya akan langsung masuk kedalam

18. Jika sudah maka masukan semua keterangan yang diinginkan kedalam rectangle

19. Selanjutnya membuat tempat untuk meletakan kartu pertanyaan dan kesempatan, caranya pilih Insert, Shapes kemudian klik Rounded Rectangle. Lalu letakan rectangle ditempat yang diinginkan.

20. Untuk mempertegas gambar buat Rounded Rectangle lagi dengan ukurann yang lebih besar, namun pada bagian fill pilih

21. Kemudian copy rectangle yang telah dibuat lalu ganti warna yang diinginkan dan tambahkan tulisan atau gambar diatasnya. Jika sudah tambahkan gambar atau tulisan diatas monopoli pembelajaran agar semakin menarik 
22. Langkah selanjutnya adalah membuat kartu pertanyaan dan kesempatan, langkah pertama klik kanan pada slide monopoli kemidan pilih New Slide, maka slide baru akan mundul

23. Jika sudah buat rectangle dengan ukuran yang kita inginkan untuk membuat kartu pertanyaan dan kesempatan, setelah itu masukan pertanyaan yang diinginkan sesuai meteri
24. Begitu juga untuk membuat bintang pilih New Slide kemudian pilih Insert, Shapes lalu cari 5-Point Star lalu klik

25. Kemudian copy 5-Point Star sampai memenuhi slide

26. Langkah terakhir yaitu tekan Ctrl dan S secara bersamaan kemudian pilih type penyimpanannya dengan JPEG setelah itu pilih Save, maka gambar siap cetak

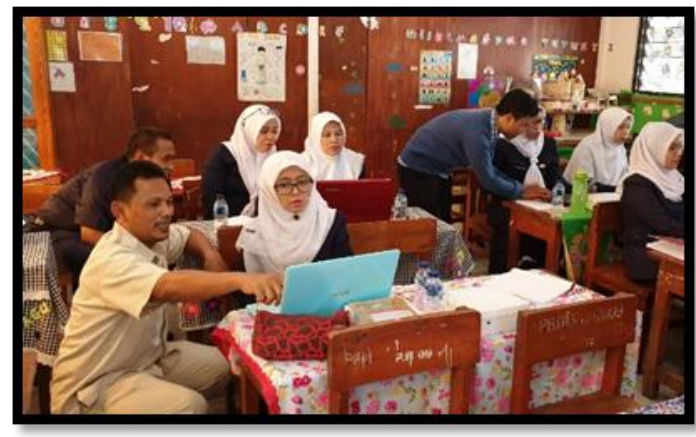

(a)

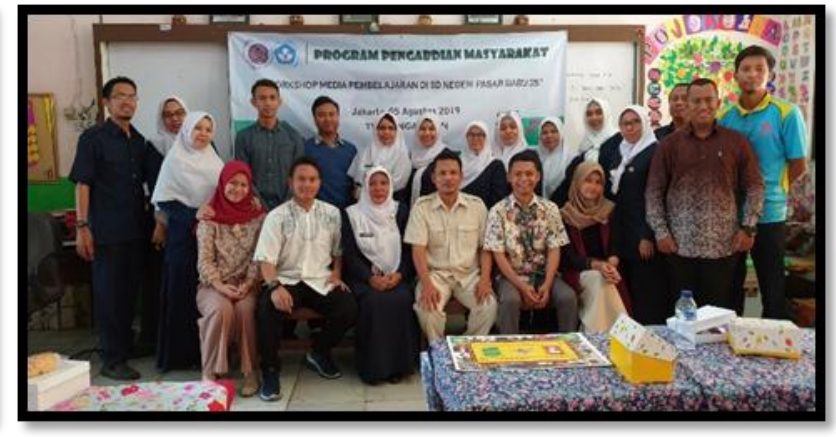

(b)

Gambar 1. (a) Proses Pembuatan Monopoli Pembelajaran sebagai Media Pembelajaran IPS, (b) Dokumentasi Kegiatan Penutupan Workshop Peningkatan Profesionalisme Guru SD

\section{KESIMPULAN \& SARAN}

Guru yang profesional adalah guru yang dapat memahami karakter peserta didik, sehingga guru mampu menyusun metode dan media pembelajaran yang menarik minat belajar peserta didik. Kemampuan membuat media, sebagai salah satu alat untuk membangkitkan semangat belajar peserta didik sangatlah diperlukan. Untuk itu guru harus terus menggali berbagai media pembelajaran yang terbarukan atau media pembelajaran yang dekat dengan peserta didik.

Monopoli sebagai suatu bentuk pernainan yang akrab dengan anak-anak. Monopoli dapat dimainkan dengan berbagai informasi didalamnya termasuk ilmu pengetahuan sosial bahkan ilmu pengetahuan alam. Monopoli dapat dirancang dan dibuat sebagai media pembelajaran sekaligus peserta didik merasa tidak bosan dalam mengikuti pembelajaran. Hal ini menjadi tugas setiap guru untuk lebih berinovasi mencari media pembelajaran yang dekat dengan peserta didik.

Setelah kegiatan pengabdian dilakukan di Sekolah Dasar Negeri Pasar Baru 05 Pagi, saran dalam kegiatan ini adalah :

a. Perguruan tinggi dan sekolah harus terus melakukan kerjasama dalam bidang peningkatan profesionalisme guru.

b. Perguruan tinggi bersama sekolah harus terus mampu berinovasi melahirkan media pembelajaran yang dekat dengan peserta didik.

c. Guru selaku ujung tombak harus dapat mengevaluasi hasil penggunan media pembelajaran yang digunakan sehingga mampu dijadikan dasar dalam membuat inovasi pembelajaran berikutnya.

d. Pihak sekolah harus memberi penghargaan kepada guru-guru yang mampu menghadirkan media pembelajaran yang baik dan bermanfaat dalam pembelajaran, sehingga guru semakin terpacu untuk menghasilkan karya-karya lainnya.

\section{DAFTAR PUSTAKA}

Elfrianto. (2016). Manajemen Pelatihan Sumber Daya Manusia dalam Meningkatkan Mutu Lulusan. Jurnal EduTech, 2(2), 46-58.

Handayani, S. (2014). Peningkatan Kompetensi Pedagogik Guru IPS Sekolah Dasar Melalui Penerapan Keterampilan Mengajar. Jurnal Ilmu Pendidikan Sekolah Dasar, 2(1), 1-15.

Harini, B., \& Usman, N. (2019). Peningkatan Keterampilan Mahasiswa PGSD FKIP Universitas Sriwijaya dalam Membuat Media Pembelajaran IPS SD Berbasis Edutainment. Jurnal Publikasi Pendidikan, 9(1), 19-27.

Harjum, A. H. (2018). Penerapan Teknik 
Supervisi Observasi Kelas Untuk Meningkatkan Kinerja Guru Dalam Pembelajaran di SD Negeri 94 Tiroang Kabupaten Pinrang Sulawesi Selatan. Jurnal Publikasi Pendidikan, 8(3), 153159.

Inggriyani, F., Fazriyah, N., Hamdani, A. R., \& Purbasari, A. (2020). Pendampingan Model Pembelajaran Inovatif menggunakan Kahoot sebagai Digital Game Based Learning di KKG Sekolah Dasar. Jurnal Publikasi Pendidikan, 10(1), 59-64.

Karmizan. (2018). Meningkatkan Kompetensi Pedagogik Guru dalam Pembelajaran dengan Lesson Study di Kelas SD Negeri 001 Koto Peraku Kecamatan Cerenti. Jurnal PAJAR (Pendidikan Dan Pengajaran) Program Studi Pendidikan Guru Sekolah Dasar FKIP Universitas Riau, 2(4), 608-618.

Khairunnisa, S., Hakam, A., \& Amaliyah. (2018). Pengembangan Media Pembelajaran Permainan Monopoli pada Mata Pelajaran Pendidikan Agama Islam. TARBAWY: Indonesian Journal of Islamic Education, 5(1), 60-69.

Mangkunegara, A. P. (2000). Manajemen Sumber Daya Manusia Perusahaan Bandung: $P T$ Remaja Rosdakarya. Bandung: PT Remaja Rosdakarya.

Muhson, A. (2004). Meningkatkan Profesionalisme Guru: Sebuah Harapan. Jurnal Ekonomi \& Pendidikan, 2(1), 90 98. https://doi.org/10.21831/jep.v1i2.665

Nurseto, T. (2011). Membuat Media Pembelajaran yang Menarik. Jurnal Ekonomi \& Pendidikan, 9(1), 19-35.

Siswono, E., \& Djulaiqha, N. (2017). Peningkatan Kompetensi Profesional Guru IPS (Studi Kasus Di MGMP IPS Kecamatan Cengkareng Jakarta Barat). Edukasi IPS, 01(1), 1-11.

Suprapto, A. N. (2013). Permainan Monopoli Sebagai Media Untuk Meningkatkan Minat Belajar tata Boga di SMA. Jurnal Ilmiah Guru “COPE, ” XVII(01), 37-43. 